\title{
POLÍTICAS PUBLICAS DE INCENTIVO AMBIENTAL E SOCIAL E A NECESSIDADE DE EFETIVAÇÃO DO “ATUAL" MODELO DE DESENVOLVIMENTO.
}

\author{
Greice Kelly L. Porfírio ${ }^{1}$ \\ Nivaldo dos Santos ${ }^{2}$
}

\begin{abstract}
Resumo:
A presente pesquisa tem como objeto analisar a evolução do conceito de desenvolvimento com base no estudo estabelecido por Vechia (2010), observando três seguimentos indissociáveis: social ambiental e econômico. Para tanto, diante da problemática levantada foram traçados três pontos: no primeiro será analisado a evolução do desenvolvimento economicamente maximizado em prol de medidas ambientalmente sustentáveis com ênfase nas políticas públicas para garantir a efetividade sob um enfoque no Programa de Patentes Verdes e o Decreto 8.874/2016, e, ainda a suspensão do Programa Piloto de Patentes Verdes e os entraves para execução de outras políticas públicas através de tecnologias verde.
\end{abstract}

Palavras-chave: Desenvolvimento Sustentável; Programa de Patentes Verdes, Tripé da Sustentabilidade; Tecnologias Verdes

\section{PUBLIC POLICIES FOR ENVIRONMENTAL AND SOCIAL INCENTIVES AND THE NEED FOR EFFECTIVENESS OF THE “CURRENT" DEVELOPMENT MODEL}

\begin{abstract}
:
This research aims to analyze the evolution of the concept of development based on the study established by Vechia (2010), observing three inseparable segments: social, environmental and economic. Therefore, in view of the problem raised, three points were outlined: the first will analyze the evolution of economically maximized development in favor of environmentally sustainable measures with an emphasis on public policies to ensure effectiveness under a focus on the Green Patent Program and Decree 8,874 / 2016, and also the suspension of the Green Patent Pilot Program and obstacles to the implementation of other public policies through green technologies.
\end{abstract}

Keywords: Sustainable development; Green Patent Program, Sustainability Tripod; Green Technologies.

\footnotetext{
${ }^{1}$ Mestre em Direito Agrário pela Universidade Federal de Goiás - UFG, Pós Graduada em Direito Civil e Direito Processual Civil, Advogada e Professora Substituta - UFG, UNIFANAP e Faculdade Anhanguera. http://lattes.cnpq.br/882403603324280

${ }^{2}$ Doutor em Direito pela Pontifícia Universidade Católica de São Paulo e Pós-Doutorado em Direito pela PUCMG. Atualmente é professor titular da Pontifícia Universidade Católica de Goiás, e da Universidade Federal de Goiás. Filiado a SBPC e ao CONPEDI. http://lattes.cnpq.br/3359203015249134
} 


\section{Introdução:}

A presente pesquisa está articulada na evolução do conceito de desenvolvimento com base no estudo estabelecido por Vechia (2010) o qual preleciona que a plenitude do caráter desenvolvimentista se estabelece observando três seguimentos indissociáveis: social ambiental e econômico.

A partir de tal perspectiva, o interesse público fundado na valorização da ordem econômica preconizado pelo artigo 170 da CF/88 deve se alinhar segundo os incisos VI e VII, as questões ambientais, sociais, resguardando os interesses dos presentes e futuras gerações.

Assim, o despertar ambiental instaurado mundialmente foi recepcionado pela Carta Magna de 1988 sendo que velhas práticas desenvolvimentistas fundadas apenas em pilares econômicos deveriam ser abandonadas em prol de uma responsabilidade com a coletividade e de novo modelo.

Diante dos anseios constitucionais de alinhar desenvolvimento de maneira sustentável existem entraves inclusive muito bem ponderados por Ulrich Beck o qual estabelece um agravamento da questão ambiental diante da fragilidade e ineficácia das políticas públicas de gestão.

Para tanto, a presente pesquisa se justiça a partir da necessidade de um novo conceito de desenvolvimento em três eixos, através de políticas públicas em especial o estímulo e a inserção de tecnologias que proporcionem benefícios ambientais e sociais relevantes, devendo inclusive serem tratadas como prioritárias nos projetos de investimento nos termos do artigo $2^{\circ}$ do Decreto 8.874/2016.

Sendo assim, levanta-se como seguinte problemática, a "prioridade nos projetos de investimentos na área de infraestrutura ou de produção econômica intensiva em pesquisa, desenvolvimento e inovação", considerando a suspensão do programa de registro de patentes verdes seria, pois, eficaz e visto como um estímulo ao cumprimento do "atual" conceito de desenvolvimento?

Diante da problemática estabelecida e objetivos traçados, por meio da revisão bibliográfica, dados e demais mecanismos para solucionar as questões anteriormente estabelecidas, a pesquisa se desenvolverá em três tópicos.

O primeiro será analisado a evolução do conceito de desenvolvimento economicamente maximizado em prol de medidas ambientalmente sustentáveis, o segundo 
ponto propor-se uma análise a partir do "tripe da sustentabilidade" na visão de Vechia com ênfase nas politicas públicas para garantir a efetividade sob um enfoque no Programa de Patentes Verdes e o Decreto 8.874/2016 que incentiva investimentos prioritários em medidas ambientais e sociais ligadas a setores energéticos, de irrigação, infraestrutura, dentre outros. E por fim no terceiro e último ponto, propõe-se analisar a suspensão do Programa Piloto de Patentes Verdes e os entraves para execução de outras políticas públicas através de tecnologias verdes.

\section{Da evolução do conceito de desenvolvimento e o abandono às práticas unicamente econômicas:}

Para falarmos em "atual" conceito de desenvolvimento é importante que se estabeleça uma análise, inclusive histórica do tema, a qual possibilita identificar o abandono de premissas meramente econômicas para fase "atual", de que falar em crescimento meramente econômico é ignorar inclusive a própria existência humana, completamente dependente dos fatores ambientais.

Para tanto, uma corrente inclusive internacional ocasionou o enfraquecimento de fatores imediatistas visando unicamente riquezas, cedendo lugar a junção dos aspectos sociais, culturais, econômicos e ambientais. Assim, os entraves existentes para efetivar e proporcionar uma produção aliada à fatores ecológicos precisam ser abandonados, momento em que é importante invocar uma das hipóteses da presente pesquisa a qual seria o uso e incentivo as tecnologias verdes como prioridade nos projetos governamentais de investimento.

Houve então um enfraquecimento do direito do desenvolvimento no aspecto voltado para as questões econômicas, principalmente no âmbito internacional, momento em que iniciam os acordos ambientais "multilaterais, sobretudo nas convenções-quadro dos anos 80, sobre clima, diversidade biológica, estabelecimentos humanos e habitat" (VARELLA, 2004 , p. 34) ${ }^{3}$. Portanto, a partir dos anos 70 se consolida a construção do desenvolvimento sustentável a qual continua a evoluir diariamente até os dias de hoje.

\footnotetext{
${ }^{3}$ Segundo Varella (2004, p.34) no direito internacional, elos entre a proteção da natureza e o desenvolvimento foram traçados desde os anos 30, citando ainda os principais eventos internacionais que promoveram a construção do desenvolvimento sustentável, sendo eles: Convenção sobre a preservação da fauna e flora, de 1933, a Convenção Internacional de para a Regulação da Caça das Baleias de 1946, e os Acordos para o estabelecimento de um Conselho Geral de Pescas para o Mediterrâneo, de 1949.
} 
Como bem mencionou Varella (2004, p. 34), o desenvolvimento até então adotado pelo mundo em que a exploração e o crescimento considerado válido era unicamente econômico, a partir dos anos 70, cede lugar a necessidade de uma conscientização ambiental mundial, o que fora claramente representado pela Conferência de Estocolmo (1972) o que segundo Mazzuoli (2010, p. 878) refere-se a um marco normativo, vejamos:

(...) o passo efetivamente concreto e de conscientização da sociedade internacional para os problemas ambientais, que começavam a emergir com intensidade desde então, e o marco normativo inicial à futura construção do sistema internacional de proteção ao meio ambiente.

A consciência ecologia foi incitada mundialmente diante de diversos desastres ambientais ao longo da história abandonando assim antigos pré-conceitos estabelecidos sobre o modelo de desenvolvimento até então utilizado.

Na Convenção das Nações Unidas sobre o Meio Ambiente Humano que ocorreu em Estocolmo, 1972, se adotou a seguinte definição como conceito de desenvolvimento sustentável:

O homem tem o direito fundamental à liberdade, à igualdade, a condições de vida adequadas, num ambiente com uma qualidade que permita uma vida com dignidade e bem-estar, e o homem porta uma responsabilidade solene na proteção e melhoria do meio ambiente para as gerações presentes e futuras.

Verifica-se que desde 1972 o mundo de depara com a necessidade de mudança sobre o modo estabelecido em relação aos preceitos econômicos e ambientais, para Morin e Kern (2003, p. 69), a partir da Convenção de Estocolmo em 1972, a sociedade começou a compreender a necessidade de "conciliar", considerando que o desenvolvimento sustentável, define a ideia de desenvolvimento precoce é "subdesenvolvida":

Trata-se de conciliar as necessidades de proteção ecológica e as necessidades de desenvolvimento econômico do terceiro mundo. A ideia de "desenvolvimento sustentável " põe em dialógica a ideia de desenvolvimento, que comporta aumento das poluições; e a ideia de meioambiente, que requer limitação das poluições. Todavia, a ideia de desenvolvimento continua ainda tragicamente subdesenvolvida; ela ainda não foi realmente repensada, mesmo na ideia de desenvolvimento sustentável. 
Ora, ao analisar os dizeres de Morin e Kern (2003, p.69) ainda mencionando sobre as dificuldades de um cenário contextualizado em 1972, percebemos o quão atual se faz a ponderação, vez que, até o presente momento a governança de políticas desenvolvimentistas ambientais não se mostra eficaz e capaz de garantir os anseios da sustentabilidade e do desenvolvimento no país.

Já em 1987 o documento denominado "Nosso Futuro Comum", também denominado "Relatório de Brundtland" fora confeccionado pela Comissão do Meio Ambiente e Desenvolvimento criada pela ONU. A partir deste se apresentaram visões críticas do modelo de desenvolvimento adotado pelos países industrializados e copiado pelos em desenvolvimento, demonstrando os riscos do uso desmedido dos recursos naturais ao ignorar a capacidade de regeneração do meio ambiente. Enfim, fora apontado uma incompatibilidade entre o desenvolvimento sustentável e os moldes de produção e consumo vigentes, trazendo inclusive um novo conceito de desenvolvimento sustentável: "o desenvolvimento que satisfaz as necessidades presentes, sem comprometer a capacidade das gerações futuras de suprir suas próprias necessidades".

Como evento mais importante do século XX, em se tratando de questões inerentes ao presente estudo, em 1992 na Cidade do Rio de Janeiro, a ONU organizou a Conferência das Nações Unidas sobre o Meio Ambiente e o Desenvolvimento, denominada também de ECO-92, Rio 92, ou Cúpula da Terra.

A Conferência trouxe diversos resultados positivos para a construção e evolução dos instrumentos ligados à exploração dos recursos naturais do mundo, bem como o desenvolvimento sustentável, são eles: Agenda 21, Convenção da Biodiversidade, Convenção das Mudanças Climáticas, Convenção da Desertificação, Declaração de Princípios sobre Florestas, a Carta da Terra e a Declaração do Rio sobre Ambiente e Desenvolvimento. ${ }^{4}$

\footnotetext{
4 "A Agenda 21 pode ser definida como um instrumento de planejamento para a construção de sociedades sustentáveis, em diferentes bases geográficas, que concilia métodos de proteção ambiental, justiça social e eficiência econômica" (MINISTERIO DO MEIO AMBIENTE, 2017).

A Convenção da Biodiversidade - Decreto Legislativo no 2, de 1994, tem como objetivos "a conservação da diversidade biológica, a utilização sustentável de seus componentes e a repartição justa e equitativa dos benefícios derivados da utilização dos recursos genéticos, mediante, inclusive, o acesso adequado aos recursos genéticos e a transferência adequada de tecnologias pertinentes, levando em conta todos os direitos sobre tais recursos e tecnologias, e mediante financiamento adequado". (MINISTERIO DO MEIO AMBIENTE, 2017) A Convenção das Mudanças Climáticas, tem como " objetivo reunir os países em um esforço conjunto para estabilizar as concentrações de gases de efeito de estufa em níveis que não impliquem alterações climáticas perigosas. Esse foi o primeiro grande passo político dos países-membros da Organização das Nações Unidas para discutir as mudanças climáticas. A Convenção entrou em vigor em 1994 e atualmente possui 192 países signatários" (MINISTERIO DO MEIO AMBIENTE, 2017).
} 
A necessidade da conscientização de todos em prol de uma sociedade sustentável se faz já do preambulo da Carta da Terra (1992, p. 1) clamando para que todos possam "escolher o seu futuro":

Estamos diante de um momento crítico na história da Terra, numa época em que a humanidade deve escolher o seu futuro. À medida que o mundo tornase cada vez mais interdependente e frágil, o futuro enfrenta, ao mesmo tempo, grandes perigos e grandes promessas. Para seguir adiante, devemos reconhecer que, no meio da uma magnífica diversidade de culturas e formas de vida, somos uma família humana e uma comunidade terrestre com um destino comum. Devemos somar forças para gerar uma sociedade sustentável global baseada no respeito pela natureza, nos direitos humanos universais, na justiça econômica e numa cultura da paz. Para chegar a este propósito, é imperativo que nós, os povos da Terra, declaremos nossa responsabilidade uns para com os outros, com a grande comunidade da vida, e com as futuras gerações

A sustentabilidade também foi abordada na Declaração do Rio sobre o Ambiente e Desenvolvimento (1992), em 24 princípios. No Princípio $3^{\circ}$ mais uma vez se reformulou o conceito de desenvolvimento sustentável:

O direito ao desenvolvimento deve ser realizado de modo a satisfazer equitavelmente as necessidades relativas ao desenvolvimento e ao meio ambiente das gerações presentes e futuras.

Assim como na Convenção de Estocolmo e no Relatório de Brundtland, a Conferência Rio 92 também deu enfoque à necessidade de ajustar o desenvolvimento com as questões ambientais, visando assegurar a ordem econômica nacional e a sobrevivência e bemestar das presentes e futuras gerações através de medidas concretas e eficazes.

Segundo informações extraídos do site do Ministério do Meio Ambiente, a Agenda 21 ao apresentar tantas medidas para crescimento e preservação ambiental pode ser definida como um “instrumento de planejamento para a construção de sociedades sustentáveis, em diferentes bases geográficas, que concilia métodos de proteção ambiental, justiça social e eficiência econômica".

A Convenção da Desertificação foi aderida pelo Brasil junto com outros 192 países. "Esse compromisso estabelece padrões de trabalho e metas internacionais convergentes em ações coordenadas na busca de soluções qualitativas que atendam às demandas socioambientais nos espaços áridos, semiáridos e subsumidos secos, particularmente onde residem as populações mais pobres do planeta". (MINISTERIO DO MEIO AMBIENTE, 2017).

A Declaração de Princípios Florestais trata-se de princípios criados na Rio 92, objetivando "contribuir para a gestão, conservação e desenvolvimento sustentável das florestas e para fornecer para as suas funções e usos múltiplos e complementares. (MINISTERIO DO MEIO AMBIENTE, 2017). 
O documento logo em seu preâmbulo, reafirma seus objetivos os quais visam preparar o mundo para desafios do século XXI, tendo como função subsidiar as ações do Poder Público e da sociedade em prol do desenvolvimento sustentável.

Assim, a agenda 21 documento redigido na Conferência Rio-92 apresenta apontamentos deixando claro a preocupação ambiental. Para tanto, como estratégia de alinhar desenvolvimento econômico a proteção ambiental, falou-se em "estímulo à difusão das tecnologias ambientalmente saudáveis já existentes e promoção da pesquisa e o desenvolvimento de tecnologias ambientalmente saudáveis" (..) visando a "redução ao mínimo da geração de resíduos" (Agenda 21, 1992).

Outro fator primordial para a presente pesquisa trazido pela Agenda 21 no item 4.1.1 do Capítulo 4, foi a necessidade de se estabelecer novos conceitos de "riqueza e prosperidade". A partir de então um novo conceito de crescimento econômico sustentável deve ser colocada em prática, de forma com que as práticas econômicas sejam menos devastadoras aos "recursos finitos da Terra", harmonizando-se com sua capacidade produtiva, promovendo assim uma expansão no conceito de desenvolvimento voltado para a preservação ambiental.

Tais medidas, segundo o documento (Agenda 21), deveriam ser aplicadas por meio da conscientização das comunidades quanto aos padrões de produção/consumo, em conjunto com políticas públicas efetivas que propagassem a utilização e transferência das tecnologias ambientalmente amigáveis/saudáveis para os países em desenvolvimento, vejamos:

\begin{abstract}
Nos anos vindouros os Governos, trabalhando em colaboração com as instituições adequadas, devem procurar atender aos seguintes objetivos amplos: (a) Promover a eficiência dos processos de produção e reduzir o consumo perdulário no processo de crescimento econômico, levando em conta as necessidades de desenvolvimento dos países em desenvolvimento; (b) Desenvolver uma estrutura política interna que estimule a adoção de padrões de produção e consumo mais sustentáveis; (c) Reforçar, de um lado, valores que estimulem padrões de produção e consumo sustentáveis; de outro, políticas que estimulem a transferência de tecnologias ambientalmente saudáveis para os países em desenvolvimento (AGENDA 21, 1992).
\end{abstract}

Portanto, através dos desdobramentos apontados pela Agenda 21, conforme mencionado anteriormente, é possível identificar as metas e modos de aplicação traçados para modelos sustentáveis de desenvolvimento que garantam os direitos das gerações presentes e 
futuras, alinhando crescimento econômico ao desenvolvimento tecnológico e sustentável, contribuindo assim com fatores elevados de produção bem como preservação do meio ambiente.

Após os 20 anos de realização da Rio-92, em junho de 2012, realizou na cidade do Rio de Janeiro- RJ, uma Conferência das Nações Unidas sobre Desenvolvimento Sustentável. O objetivo da Conferência foi a renovação dos compromissos já firmados com o desenvolvimento sustentável, onde se avaliou o progresso das metas traçadas na Rio-92, bem como apresentou tratativas à novos temas.

O documento oficial final produzido na Rio+20 foi chamado de "The Future We Want”, ou o Futuro que Queremos, neste, foi reconhecida a necessidade de agregar os aspectos econômicos, sociais e de proteção/preservação ambiental:

\begin{abstract}
Afirmamos, portanto, a necessidade de uma melhor integração dos aspectos econômicos, sociais e ambientais do desenvolvimento sustentável em todos os níveis, e reconhecemos as relações existentes entre esses diversos aspectos para se alcançar o desenvolvimento sustentável em todas as suas dimensões (RIO+ 20, 2012).
\end{abstract}

A necessidade de inserções tecnológicas através de políticas públicas de incentivo no aspecto ambiental e social também foram palco para o aludido documento. Portanto, as metas traçadas desde a Rio-92 foram ratificadas pela Rio+20, tendo como principal fundamento a junção dos três preceitos para que o desenvolvimento nacional já idealizado pela Constituição Federal de 88 seja cumprido observando também as questões ambientais.

Para tanto, vale ressaltar que as normas ambientais que desde a década de 70 vem sendo idealizadas a nível mundial foram recepcionadas pela Carta Magna de 88, sendo que, a partir de então adquiriram o status constitucional. A principal norma de proteção ambiental no direito brasileiro está disposta no artigo $225^{5}$, caput da Constituição Federal de 1988, que garante aos cidadãos o direito fundamental ao meio ambiente "ecologicamente equilibrado".

\footnotetext{
5 Art. 225- Todos têm direito ao meio ambiente ecologicamente equilibrado, bem de uso comum do povo e essencial à sadia qualidade de vida, impondo-se ao Poder Público e à coletividade o dever de defendê-lo e preserva- ló para as presentes e futuras gerações.

$\S 1^{\circ}$ Para assegurar a efetividade desse direito, incumbe ao Poder Público:

V - controlar a produção, a comercialização e o emprego de técnicas, métodos e substâncias que comportem risco para a vida, a qualidade de vida e o meio ambiente (BRASIL, 1988).
} 
Da leitura dos artigos $170 \mathrm{VI}^{6}$ e do $225 \S 1^{\circ} \mathrm{V}$ da Constituição Federal, decorre o princípio do desenvolvimento sustentável.

Como bem dispõe os autores Sarlet e Fensterseifer (2008, p.196), a atual tendência é da proteção constitucional e legal para todos os recursos naturais, inclusive contra atos praticados pelo próprio ser humano, o que demonstra que todas as formas de vida devem viver com dignidade.

Vale constar, observando a evolução histórica apresentada, que por muitos anos o homem ignorou os recursos naturais priorizando apenas sua evolução economia imediata. Carson (2010), em sua obra Primavera Silenciosa, demonstra quão vulnerável se tornou a natureza frente as intervenções do homem:

\begin{abstract}
A história da vida sobre a terra tem sido uma história de interação entre as coisas vivas e seu meio ambiente. Em grande parte, a forma física e os hábitos de vegetação da terra, bem como a sua vida animal foram moldados pelo seu meio ambiente. Tornando-se em consideração a duração toda do tempo terrenal, o efeito oposto, em que a vida modifica, de fato, o seu meio ambiente, tem sido relativamente breve. Apenas dentro do momento de tempo representado pelo século presente é que uma espécie - homem adquiriu capacidade significativa para alterar a natureza do seu mundo (CARSON, 2010, p. 15).
\end{abstract}

A humanidade ao longo dos anos adquiriu a condição de transformar, criar, enfim, reinventar o seu espaço, tais fatores derivados dos conhecimentos transmitidos de geração em geração, da vida em comunidade, do conhecimento científico, dentre outras questões, segundo Pacífico (2009, p. 33), “fizeram do homem um dominador e um manipulador de animais e plantas".

Assim, apesar de existir interação entre as coisas vivas e o seu meio ambiente, como bem demonstra Carson (2010, p. 15) "o homem adquiriu capacidade significativa para alterar a natureza do seu mundo (..) esta capacidade não somente aumentou, mas também se modificou quanto ao caráter", ocasionando diversas catástrofes ambientais e sociais em todo o planeta.

\footnotetext{
${ }^{6}$ Art. 170- A ordem econômica, fundada na valorização do trabalho humano e na livre iniciativa, tem por fim assegurar a todos existência digna, conforme os ditames da justiça social, observados os seguintes princípio: VI defesa do meio ambiente, inclusive mediante tratamento diferenciado conforme o impacto ambiental dos produtos e serviços e de seus processos de elaboração e prestação; (BRASIL, 1988).
} 
Diante de tamanhos desmazelos e consequências decorrentes do imediatismo e anseio pelo desenvolvimento econômico rápido e como único fator relevante, surge diante de uma necessidade de todos, a preocupação quanto a preservação ambiental, por se tratar de uma questão de sobrevivência.

Ou seja, apenas diante de caos, o homem se mobilizou para discussão da necessidade de desenvolvimento. Contudo, em termos práticos pouco tem se evoluído na efetivação das propostas frutos das Conferências internacionais e inclusive políticas públicas nacionais que se esbarram em entraves para efetivação, podendo falar inclusive em um desenvolvimento precoce idealizado por visões "subdesenvolvidas" (MORIN E KERN, 2003, p. 69).

Para Bobbio (1992, p.6), o direito ao meio ambiente saudável é também patrimônio das futuras gerações, e seria impensável no passado:

Os direitos de terceira geração, como o de viver num ambiente não poluído, não poderiam ter sido sequer imaginados quando foram propostos os de segunda-geração, do mesmo modo como estes últimos (por exemplo, o direito à instrução ou à assistência) não eram sequer concebíveis quando foram promulgadas as primeiras declarações setecentistas. Essas exigências nascem somente quando nascem determinados carecimentos. Novos carecimentos nascem em função da mudança das condições sociais e quando o desenvolvimento técnico permite satisfazê-lo.

Conforme demonstrado ao longo da evolução histórica apresentada, a partir de uma mobilização mundial, desde a década de 70 através da Conferência de Estocolmo, os olhares do mundo se voltaram para a necessidade de que o desenvolvimento só seria efetivo se abarcasse as questões de preservação ambiental.

Nascimento (2014, p. 629), ao falar em desenvolvimento sustentável como sendo personagem de um novo campo socioambiental, demonstra que tal mecanismo foi a melhor resposta, construída pelos indivíduos como solução à crise ambiental, entendida desde a década de 70 como ameaça às condições de vida da humanidade. Como bem ponderou BOBBIO (1992), as iniciativas surgem a partir dos problemas. Contudo, é preciso dar aplicabilidade as metas apontadas ao logo dos anos.

Nesse contexto, ao pensar o desenvolvimento sustentável voltado para a questão de políticas públicas efetivas e a inserção de tecnologias verdes, Lemos (2012, p. 50-51) enfatiza que significa utilizar um conjunto de instrumentos, os quais com o auxílio de 
tecnologias ambientalmente amigáveis tem por objetivo compatibilizar a atividade econômica com a proteção ambiental.

Até mesmo porque, é possível constatar que o despertar para as questões ambientais desde a Rio-92, surge com a proposta das "tecnologias amigáveis" visando garantir o desenvolvimento, contudo em termos práticos a efetividade resta completamente comprometida. Assim, hoje após 24 (vinte quatro) anos, não estariam a sociedade e o poder público atrasados na efetividade/aplicabilidade de tais medidas?

Verifica-se que as políticas públicas realizadas tentam estimular e colocar em pratica os anseios para um efetivo desenvolvimento sustentável se deparam com vários entraves dos próprios cidadãos que desconhecem as medidas, dos governantes que muitas vezes agem de forma contrária ao trazido pela Carta Magna.

Por exemplo, o Decreto 8.874/2016 o qual regulamento as condições de aprovação dos projetos de investimento considerados como prioridade na área de produção econômica intensiva em pesquisa, desenvolvimento e inovação inseriu desde 2020 através do decreto 10.387, prioridade para os benefícios ambientais ou sociais relevantes. Contudo, em contraponto o programa de patentes verdes o qual protege e estimula a inovação tecnológica encontra-se suspenso.

Ora, se a intensão da politica pública é priorizar os investimentos e garantir os anseios constitucionais de desenvolvimento e preservação ambiental, por qual motivo atualmente o Programa de Patentes Verdes o qual facilita o registro de tecnologias ambientalmente amigáveis encontra-se suspenso?

Assim, verifica-se que ao longo do tempo a proteção ambiental se tornou um elemento imprescindível do processo desenvolvimentista, sendo que, não é possível considerar "desenvolvimento" questões não-sustentáveis, vez que caso assim não fosse, a liberdade das gerações futuras estaria comprometida. Contudo, conforme será analisado e enfrentado ao logo da presente pesquisa as políticas públicas se divergem no seu modo prático e acabam por comprometer a efetividade e a seriedade das ações.

Como bem dispõe Varella (2004, p. 43) ao ignorar tal cenário estamos diante de um retrocesso, até mesmo porque, o desenvolvimento está diretamente relacionado a necessidade de uma preservação ambiental, o que inclusive garante a existência de toda espécie humana. 


\section{2- O tripé da sustentabilidade e as políticas públicas:}

Conforme demonstrado anteriormente, desde a década de 70 o mundo se voltou para uma preocupação ambiental, estabelecendo uma corrida para que seja efetivado o novo conceito de desenvolvimento sustentável.

Assim, o conceito de desenvolvimento foi reformulado e a partir de então foram inseridas questões equivalente e indissociável dos três seguimentos: social, ambiental e econômicos.

O termo sustentabilidade é uma expressão originária do século $\mathrm{XX}$, o qual segundo descrição contida no dicionário Aulede e Valente (2007), pode ser definido como:

(...) qualidade ou condição de sustentável, associando-a modelo de desenvolvimento que busca conciliar as necessidades econômicas, sociais e ambientais de modo a garantir seu atendimento por tempo indeterminado e a promover a inclusão social, o bem-estar econômico e a preservação dos recursos naturais.

Vechia (2010) define tal alinhamento dos três fatores (social, ambiental e econômico) como tripe-bottom line ou tripé da sustentabilidade, criado pelo inglês John Elhingtin em 1994. Segundo o autor, para que seja realizado um completo e perfeito desenvolvimento sustentável nas atividades capitalistas faz-se imprescindível que exista uma harmonia entre os três pontos. Contudo, o que se presencia, em sua grande maioria, é um conflito de interesses entre elas o que acaba por dificultar a perfeita aplicabilidade do sistema.

Afirma ainda o autor (VECHIA 2010), que caso se de ênfase apenas nas questões econômicas como por muito tempo foi feito, estaríamos sujeitos a uma catastrófica degradação ambiental, ao passo que, caso se priorize apenas fatores sociais e ambientais até mesmo a segurança alimentar do individuo poderia ser prejudicada assim como questões econômicas.

Portanto, é imprescindível a evolução simultânea das três áreas (ambiental, social e econômica), para produzir o desenvolvimento sustentável. 
Ao falar em tripé da sustentabilidade, apresenta-se um conceito de sociedade sustentável a qual visa um futuro prospero para todos, garantindo a partir do desenvolvimento histórico-cultural o bem-estar dos indivíduos e de todo o ambiente, garantindo também condições de vida digna para as futuras gerações.

Dessa maneira, para ser sustentável é preciso que a iniciativa humana seja ecologicamente correta, socialmente séria, economicamente exequível e culturalmente admitida.

Colocada dessa forma, os "tripés" da sustentabilidade devem ser analisados da seguinte forma: a primeira dimensão seria a questão ambiental, a qual implica em um modo de produção/consumo que venha a garantir ao meio ambiente condições para sua auto recuperação. Em segundo momento, aparece o fator econômico, onde se propõe uma eficiência nos moldes de produção e consumo, com estimulo e aumento na economia de recursos naturais.

Segundo Rifikin (2012), seria o que se denomina de eco eficiência, supondo uma continua inovação de tecnologias, que possibilitem desvincular a produção dos compostos fósseis de energia (petróleo, gás e carvão).

Por fim, tem-se os aspectos sociais. Em uma comunidade sustentável, é imprescindível que todos os indivíduos possuam requisitos mínimos para uma vida digna, com justiça social.

Portanto, atual modelo capitalista econômico, voltado para externalidade do sistema ocasiona a crescente ameaça de um embate socioambiental, onde os recursos naturais poderiam se esgotar a qualquer momento, fenômeno que segundo Beck (2001), se denomina “sociedade de risco". ${ }^{7}$ Diante de tal cenário, é imprescindível que o Estado exerça o seu poder dever de proteção.

Como forma de inserir atividades sustentáveis efetivas dentro da esfera nacional é imprescindível governanças que provoquem medidas e oportunizem materializem os anseios de um desenvolvimento observando o tripe da sustentabilidade.

Tais deveres de cuidado do estado têm a natureza de princípio, considerando que, exigem ampla proteção dentro das condições fáticas e jurídicas existentes, sendo os deveres

\footnotetext{
7 "Sociedade de Risco", segundo Ulrich Beck (2001), refere-se a fase final do desenvolvimento da sociedade moderna, momento em que os perigos de cunho sociais, políticos, ecológicos e individuais criados em decorrência de inovações tecnológicas fogem do controle das instituições responsáveis pela proteção da sociedade.
} 
fundados não apenas em decorrência do indivíduo, mas de toda a coletividade de cidadãos (ALEXY, 2012).

Política pública pode ser conceituada como "Estado em ação", por meio de programas, métodos e ações coordenadas. Frey (2000, p. 212), preleciona que as análises de políticas envolvem ciclos, o agir público estabelece fases de formulação, implementação e controle dos impactos em um processo político e administrativo de resolução de impasses.

Para compreender a política pública é preciso analisar sua dimensão institucional (polity), que diz respeito à análise das construções políticas; processual (politics), que estabelece os processos de disputa de acesso ao poder; e material (policy), que se refere a forma de agir do Estado, por meio de suas ações. É importante lembrar, que as três ações estão entrelaçadas e, portanto, não devem ser vistas de forma isolada (FREY 2000, p. 212).

De forma simplificada, Bucci (2006, p. 39), explana sobre o conceito de política pública:

Política Pública é o programa de ação governamental que resulta de um processo ou conjunto de processos juridicamente regulados - processo eleitora, processo de planejamento, processo de governo, processo orçamentário, processo legislativo, processo administrativo, processo judicial - visando coordenar os meios à disposição do Estado e as atividades privadas, para a realização de objetivos socialmente relevantes e politicamente determinados.

Como tipo geral, a política pública deve visar a realização de objetivos definidos, expressando a seleção de prioridades, a reserva de meios necessários à consecução e o intervalo em que se espera o atingimento dos resultados.

Assim, a política pública seria a concretização de preceitos constitucionais, sendo, portanto, o cumprimento de um dever, de ações legalmente preestabelecidas, visando o bemestar social, e a dignidade da pessoa humana.

Com a promulgação da Constituição Federal de 1988, o Estado brasileiro ganhou nova roupagem com a inserção de novos instrumentos de gestão social das políticas públicas, onde se pode destacar a "institucionalização dos conselhos gestores de políticas setoriais ou conselhos de políticas públicas nas esferas federal, estaduais e municipais" (SCHNEIDER; SILVA; MARQUES, 2009, p. 6).

Contudo, apesar de se tratar de atribuições dos três entes da Federação, o processo de elaboração de políticas públicas não deve ocorrer sem a participação ativa da sociedade civil, assim como dos entes federativos: 
Fruto da mobilização de grupos sociais organizados dos mais diversos setores da sociedade brasileira, esses novos espaços de formulação gestão, controle e avaliação de políticas públicas e de concertação dos interesses de diferentes setores, uma experiência recente para o Estado e para a sociedade brasileira, tem sido ao longo dos últimos 16 anos um espaço privilegiado de exercício da cidadania e da democracia, do mesmo modo que tem sido utilizado como espaço de legitimação e de redefinição dos mecanismos de dominação de elites sociais através de processos de participação seletiva (SCHNEIDER; SILVA; MARQUES, 2009, p. 6).

A participação social nos processos de controle, elaboração das políticas e ações governamentais foi uma das principais lutas de agentes sociais e políticos no processo de redemocratização brasileiro.

Nesse sentido, é preciso que não se dê uma concentração excessiva ao papel dos governos, ignorando possibilidades de cooperação que podem ocorrer entre governos e outras instituições e grupos sociais, conforme demonstrado anteriormente. (SOUZA, 2007).

Os direitos sociais estão constitucionalmente previstos no artigo $6^{\circ}$ da Constituição Federal de 1988, quais sejam: educação, saúde, alimentação, trabalho, moradia, lazer, segurança, previdência social, proteção à maternidade e a infância e assistência aos desamparados (definidos por programas na $\mathrm{CF} / 88$ ). Em relação a proteção ambiental, o artigo 225 da $\mathrm{CF} / 88^{8}$, tratou por cuidar de um direito que é de todos, indistintamente, o uso de do meio ambiente saudável e ecologicamente equilibrado, o qual é definido pela carta como bem essencial de todos, fundamental a qualidade de vida sadia.

\footnotetext{
${ }^{8}$ Art. 225. Todos têm direito ao meio ambiente ecologicamente equilibrado, bem de uso comum do povo e essencial à sadia qualidade de vida, impondo-se ao Poder Público e à coletividade o dever de defendê-lo e preserva- lo para as presentes e futuras gerações.

$\S 1^{\circ}$ Para assegurar a efetividade desse direito, incumbe ao Poder Público:

I - preservar e restaurar os processos ecológicos essenciais e prover o manejo ecológico das espécies e ecossistemas;

II - preservar a diversidade e a integridade do patrimônio genético do País e fiscalizar as entidades dedicadas à pesquisa e manipulação de material genético

III - definir, em todas as unidades da Federação, espaços territoriais e seus componentes a serem especialmente protegidos, sendo a alteração e a supressão permitidas somente através de lei, vedada qualquer utilização que comprometa a integridade dos atributos que justifiquem sua proteção;

IV - exigir, na forma da lei, para instalação de obra ou atividade potencialmente causadora de significativa degradação do meio ambiente, estudo prévio de impacto ambiental, a que se dará publicidade;

V - controlar a produção, a comercialização e o emprego de técnicas, métodos e substâncias que comportem risco para a vida, a qualidade de vida e o meio ambiente;

VI - promover a educação ambiental em todos os níveis de ensino e a conscientização pública para a preservação do meio ambiente;

VII - proteger a fauna e a flora, vedadas, na forma da lei, as práticas que coloquem em risco sua função ecológica, provoquem a extinção de espécies ou submetam os animais a crueldade.
} 
Visando assegurar a efetividade do direito a um meio ambiente ecologicamente correto, o artigo $225, \S 1^{\circ}$, I a VII, do texto Constitucional de 1988 , estabeleceu as incumbências do poder público, para preservação, fiscalização e controle dos acontecimentos ambientais.

Assim, a Constituição Federal de 1988 consagrou como obrigação do Poder Público a defesa preservação e garantia de efetividade do direito fundamental ao meio ambiente ecologicamente equilibrado, sendo este um bem de uso comum do povo. ${ }^{9}$

Portanto, através do presente estudo verifica-se um avanço no conceito de desenvolvimento partindo de uma visão inicial meramente econômica e exploratória, e chegando a uma necessidade mundial de desenvolver observando questões sociais, ambientais e econômicas.

Para tanto, as políticas públicas são instrumentos de efetivação, divulgação e materialização de tal perspectiva, devendo o poder publico agir com coerência visando sanar os entraves para que a proteção socioambiental seja efetiva.

Considerando o desenrolar do estudo, constatou-se que desde a Rio-92, fala-se em tecnologias como forma de garantir desenvolvimento sustentável. Assim, como forma de demonstrar e comprovar o proposto, será analisado a seguir as tecnologias verdes as quais o registro era incentivado através do Programa de Patentes Verdes que se encontra suspenso e o Decreto 8.874/2016 o qual preconiza a prioridade nos investimentos de expansão para questões ambientais e sociais.

Ao suspender o Programa Piloto de Patentes Verdes, o poder público estaria sendo coerente com os dizeres constitucionais que visam em reiteradas passagens alinhar desenvolvimento econômico e sustentável?

\section{3- A suspensão do Programa de Patentes Verdes e os entraves para cumprimento das políticas públicas através das tecnologias ambientalmente amigáveis:}

Apenas com o intento de situar o leitor sobre o desenrolar do texto, verificou-se a o clamar mundial desde a década de 70 para que uma nova forma de desenvolvimento respeitando o meio ambiente fosse implementado e efetivado.

\footnotetext{
${ }^{9}$ Direito fundamental ao meio ambiente saudável: STF - Como salientado pelo Min. Celso de Mello, "essa prerrogativa consiste no reconhecimento de que todos têm direito ao meio ambiente ecologicamente equilibrado. (RE 134.297-SP, Rel. Min. Celso de Mello).
} 
Posteriormente, novas teorias e formas de aplicação do chamado desenvolvimento sustentável foram repensadas na tentativa de mudança do cenário apontado por Morin e Kern (2003, p.69) de que a ideia de desenvolvimento sustentável seria "subdesenvolvida".

Assim, chegamos até os preceitos de Vechia (2010) inspirado pelo inglês John Elhingtin (1994), traçando o tripé da sustentabilidade o que deverá ser efetivado através de governanças, políticas publicas eficientes.

O Decreto n. 8.874 de outubro de 2016, alterado pelo recente Decreto 10.387/2020 o qual regulamenta condições prioritárias para aprovação de investimentos inclusive para produção de pesquisa e desenvolvimento de inovações elenca dentro do que se considerada "prioritário" os quais "proporcionem benefícios ambientais ou sociais relevantes", vejamos o artigo $2^{\circ}$ :

Art. $2^{\circ}$ São considerados prioritários os projetos de investimento na área de infraestrutura ou de produção econômica intensiva em pesquisa, desenvolvimento e inovação:

II - que proporcionem benefícios ambientais ou sociais relevantes; ou (Redação dada pelo Decreto ${ }^{\circ}$ 10.387, de 2020).

$\mathrm{O}$ ato do poder público federal, trata-se de mais um mecanismo visando inserir questões ambientais dentro da perspectiva desenvolvimentista ${ }^{10}$. Contudo, dentro do preambulo do Decreto verifica-se que o estímulo e cumprimento da pesquisa ambientalmente e socialmente adequado poderá restar completamente ineficaz diante da atual suspensão do Programa Piloto de Patentes Verdes.

Para que seja possível compreender questões sobre tecnologias verdes, é imprescindível definir seu conceito e características. O Fórum Nacional de Gestores Inovação e Transferências - FORTEC (2012), caracteriza as tecnologias verdes como sendo a “aplicação do conhecimento para fins práticos e amigáveis com o próprio meio ambiente e até mesmo inspirada na própria natureza".

Assim, estaríamos diante de técnicas/conhecimentos capazes de superar os efeitos da já avançada degradação ambiental instaurada pelo homem sobre o planeta e seus recursos naturais (FORTEC, 2012).

\footnotetext{
${ }^{10}$ Segundo o Artigo $2^{\text {a }} \S 1^{\circ}$ do Decreto $8.874 / 2016$, os projetos de investimento com caráter prioritário envolvem os seguintes setores: logística e transporte; mobilidade urbana; energia; telecomunicações; radiodifusão; saneamento básico; e irrigação, o que poderá perfeitamente ser contemplado através de tecnologias verdes.
} 
A partir das questões anteriormente apontadas quanto as tecnologias verdes e políticas publicas de incentivo a pesquisa e desenvolvimento ambiental, o Programa Piloto de Patentes Verdes ${ }^{11}$ se apresentou como investimento Estatal para a obtenção do progresso socioambiental, por meio de inovações tecnologias, como soluções eficazes para os problemas ambientais.

Dentro dos eixos de tecnologias verdes que foram abarcadas pelo programa piloto para subscrição estavam: energias alternativas, transporte, conservação de energia e gerenciamento de resíduos e agricultura.

Assim, o Programa de Patentes Verdes brasileiro possui grande potencial como viés de incentivo a produção de tecnologias verdes, reduzindo o tempo de análise das solicitações de registro, gerando grande incentivo aos investidores na área ambiental pela possibilidade de obter retornos financeiros através da exploração e aplicação comercial das técnicas amigáveis.

As patentes verdes representam um incentivo em pesquisa e desenvolvimento, se tratando ainda de um vínculo entre o desenvolvimento e inovação desafiando os modelos de negócio no presente e futuro, vejamos:

A criação de inovações sustentáveis envolve prover e estimular visões
alternativas do mundo; assegurar o elo entre o desenvolvimento da inovação
e seu valor na cadeia produtiva; procurar novas plataformas, assim como
aperfeiçoar as já existentes; estimular o empreendedorismo, envolvendo
estudantes e profissionais de diferentes gerações; promover pequenos
negócios sem perder de vista sua reprodutibilidade para obter ganhos de
escala; e, por fim, desafiar os modelos de negócios com cenários alternativos
de futuro. (ALMEIDA, 2007, p. 171).

Contudo, a suspensão do mesmo, atualmente se mostra uma contradição inclusive com políticas de incentivo à pesquisa e ao desenvolvimento conforme Decreto n. 8.874 de outubro de 2016, alterado pelo recente Decreto 10.387/2020.

Ademais, diante dos pontos traçados é possível perceber a necessidade de alinhar as políticas públicas e o modelo de governança ambiental para cumprir aos anseios do artigo 170 da Constituição Federal quanto a ordem econômica de maneira sustentável, contudo, para

\footnotetext{
${ }^{11}$ A conceituação de patente pode ser extraída dos dizeres de Barbosa (2012, p.295): "É um direito, conferido pelo Estado, que dá ao seu titular a exclusividade da exploração de uma tecnologia. Como contrapartida pelo acesso do público ao conhecimento dos pontos essenciais do invento, a lei dá ao titular da patente um direito limitado no tempo, no pressuposto de que é socialmente mais produtiva em tais condições a troca da exclusividade de fato (a do segredo da tecnologia) pela exclusividade temporária de direito".
} 
tanto é imprescindível fomentar as pesquisas de tecnologias ambientalmente amigáveis sendo as patentes verdes um importante instrumento garantidor de proteção, desenvolvimento e estímulo as invenções.

\section{Conclusão:}

A partir de uma análise histórica da evolução desenvolvimentista em termos mundiais, constatou-se que em decorrência de um desenvolvimento econômico maximizado até meados da década de 70 ocasionou impactos ambientais.

De um lado a negação do valor da natureza e, por outro, a crença de que o progresso tecnológico seria capaz de controlar as forças naturais. Os resultados desse processo ocasionaram uma crise ambiental globalizada.

A partir de tal cenário, o desenvolvimento baseado apenas em questões econômicas se tornou obsoleto e inadequado. O conceito de desenvolvimento sustentável trazido já em 1972 na Conferência de Estocolmo representou um marco internacional, contudo, os entraves para sua efetividade ainda se fazem presentes hoje em 2021.

O ilustre pesquisador Morin, refletindo sobre o tema menciona que as teorias do desenvolvimento sustentável não são palpáveis para a implementação prática do instituto demonstrando algo imaturo precoce, o que nomeou de "subdesenvolvimento".

Como resposta aos questionamentos levantados, a partir de uma política pública de incentivo para prática do medidas sociais e ambientalmente adequadas (Decreto 8.874/2016), foi possível constatar que o Programa Piloto de Patentes Verdes, representou uma aliança entre o desenvolvimento tecnológico e sustentável e que o mesmo se mostra capaz de estimular e proteger invenções tecnologias em prol do meio ambiente, efetivando inclusive os anseios de outras medidas públicas como a trazida pelo Decreto 8.874/2016.

Trata-se de um retrocesso a atual suspensão do Programa Piloto de Patentes, simplesmente porque as outras formas tradicionais de registro das invenções verdes são burocráticas, e acabam impactando no resultado final de uso e divulgação das técnicas, que por muitas vezes quando são patenteadas já se tornaram obsoletas ou caíram em desuso.

Portanto, foi possível perceber a necessidade de inter-relacionar as políticas públicas ambientais, as quais estimulam a criação de novas tecnologias e o seu uso para 
conter problemas ambientais, atendem a uma perspectiva globalizada de informação e desenvolvimento.

\section{REFERÊNCIAS:}

ALMEIDA, Fernando. Os desafios da sustentabilidade: uma ruptura urgente. Rio de Janeiro: Elsevier, 2007.

ANTUNES, P. B. Evolução do Direito e da política do Ambiente Internacional, Comunitário e nacional. Revista Millenium, n. 7, ano II, p. 32-35. Viseu: Escola Superior de Tecnologia de Viseu, 1997.

BARBOSA, D.B. Uma introdução à propriedade intelectual.2 ed.São Paulo, SP: Lumen Juris, 2012.

BARRAL, W. Direito e Desenvolvimento: Análise da ordem jurídica brasileira sob a ótica do desenvolvimento. São Paulo: Singular, 2005.

BRASIL. Constituição da República Federativa do Brasil de 1988. Disponível em: http://www.planalto.gov.br/ccivil_03/constituicao/ConstituicaoCompilado.htm. Acesso em 10 Fev 2021.

BRASIL. Decreto 8.874 de 11 de Outubro de 2016. Regulamenta as condições para aprovação dos projetos de investimento considerados como prioritários na área de infraestrutura ou de produção econômica intensiva em pesquisa, desenvolvimento e inovação. Disponível em: http://www.planalto.gov.br/ccivil_03/_Ato20152018/2016/Decreto/D8874.htm

BRASIL. Ministério do Meio Ambiente. Agenda 21. Disponível em: <http://www.mma.gov.br/responsabilidade-socioambiental/agenda-21/agenda-21-global. Acesso em 03 de Mar 2021.

BRASIL. Ministério do Meio Ambiente. Carta da Terra. Disponível em: < http://www.mma.gov.br/estruturas/agenda21/_arquivos/carta_terra.pdf $>$. Acesso em $07 \mathrm{de}$ Mar 2021.

BRASIL. Ministério do Meio Ambiente. O futuro que Queremos. Disponível em: http://www.mma.gov.br/port/conama/processos/61AA3835/O-Futuro-que queremos1.pdf. Acesso em 25 de Mar 2021.

BAUMAN, Z. Vidas Desperdiçadas. Tradução Carlos Alberto Medeiros. Rio de Janeiro. 2004.

BOBBIO, N. A era dos direitos. Rio de Janeiro: Campus, 1992. 
BUTZKE, A; HOFFMANN E. W. Desenvolvimento e sustentabilidade: o grande conflito de nossos dias. Revista Direito e Justiça: reflexões sócio jurídicas. Universidade Regional Integrada do Alto Uruguai e das Missões: Santo Ângelo. Ediuri, a. VI, n. 9, pp. 43-61, nov. 2006.

CARLETTO, M.R. Avaliação de Impacto Tecnológico: Reflexões, Fundamentos e Práticas. $1^{\text {a }}$ ed. Curitiba: UTFPR, 2011.

CARSON, R. L. Primavera Silenciosa. "Tradução Claudia Sant'Ana Martins." São Paulo: Gaia, 2010.

DERANI, Cristiane. Direito ambiental econômico. 3. ed. São Paulo:Saraiva, 2008.

LIMA, André Rodolfo. Introdução ao Direito Socioambiental. In: O direito para o Brasil socioambiental. Org. André Lima. Porto Alegre: Sergio Antonio Fabris Editor, 2002. p.21 a 53.

MAZZUOLI, Valério de O. Curso de Direito Internacional público, $4^{\text {a }}$ Ed. São Paulo: Revista dos Tribunais, 2010

MILARE, E. Direito do Ambiente. A gestão ambiental em foco. $5^{a}$.ed. São Paulo: Saraiva, 2004.

MORRIN, E; KERN, A. B. Terra - Pátria. Tradução de Paulo Neves. Editora Sulina. Porto Alegre, 2003.

NOZICK, Robert. Anarquia, Estado e Utopia. Rio de Janeiro: Jorge Zahar, 1991

ONU, Programa das Nações unidas para o Desenvolvimento - PNUD - disponível https://pnudbrasil.exposure.co/relatorio-anual. Acesso em: 04. Abr. 2021.

SACH, Ignacy. Rumo à ecossocioeconomia: teoria e pratica do desenvolvimento. Organização de Paulo Freire Vieira. São Paulo, 2007.

SARLET, Ingo W: FENSTERSEIFER, Tiago. Direito Constitucional Ambiental. São Paulo: Revista dos Tribunais, 2011.

SEM, Armatya. Desenvolvimento como liberdade. São Paulo. Companhia das Letras, 2000.

SIQUEIRA, TAGORE VILLARIM DE. Desenvolvimento Sustentável: Antecedentes Históricos e Propostas para a Agenda 21. Disponível em: http://www.bibliotecaflorestal.ufv.br/bitstream/handle/123456789/4214/BNDES Desenvolvi mento-sustent\%C3\%A1vel-antecedentes-e-propostas-para-a-Agenda 21.pdf?sequence=1\&isAllowed=y. Acesso em: 06 set. 2016.

SOARES, G.F.S. A proteção Internacional Ambiental. São Paulo: Manole, 2003. 
VARELLA, M. D. Direito Internacional Econômico Ambiental. Belo Horizonte: Del Rey, 2004.

VECCHIA, Rodnei. O meio ambiente e as energias renováveis: instrumentos de liderança visionaria para a sociedade sustentável. Barueri - SP: Manole: Minha Editora, 2010.

VEIGA, J.E. da. Meio Ambiente do Século 21: 21 especialistas falam da questão ambiental nas suas áreas do conhecimento. $4^{\mathrm{a}}$ Ed. São Paulo: Amazém do Ipê, 2008. p. 200/2013. 